\title{
INTERCULTURALIDADE NA PERSPECTIVA DA DESCOLONIALIDADE: POSSIBILIDADES VIA EDUCAÇÃO
}

\author{
INTERCULTURALIDAD EN LA PERSPECTIVA DE LA DESCOLONIALIDAD: \\ POSIBILIDADES TRAVÉS DE LA EDUCACIÓN
}

\section{INTERCULTURALITY IN THE PERSPECTIVE OF DESCOLONIALITY: POSSIBILITIES SINCE THE EDUCATION}

\author{
João Alberto Steffen MUNSBERG ${ }^{1}$ \\ Gilberto FERREIRA DA SILVA ${ }^{2}$
}

RESUMO: Este artigo explora a questão da interculturalidade no campo da educação desde as contribuições oriundas da produção do Grupo Modernidade/Colonialidade, sob a perspectiva da descolonialidade. Resulta de um processo de discussão realizada pelo coletivo de pesquisadores vinculados ao Grupo de Pesquisa em Educação Intercultural do Unilasalle. Lança-se mão da literatura disponível para a construção da reflexão, com especial ênfase aos textos de Mignolo, Quijano e Restrepo/Rojas. Os pressupostos desses pensadores apontam para a proposição de uma "episteme outra", pensada desde o lugar do subalternizado. Constata-se que a educação intercultural se constitui em possível fator propulsor da descolonização, remetendo para a construção de uma "sociedade outra" mediante a superação de velhos discursos, de estruturas excludentes e de posturas discriminatórias. Nessa perspectiva, a interculturalidade propicia a convivência de sujeitos e de sociedades plurais, de culturas múltiplas. Não obstante, a realidade no campo da educação intercultural continua como desafio na busca de um "outro mundo possível".

PALAVRAS-CHAVE: Descolonialidade. Interculturalidade. Educação intercultural. Geopolítica do conhecimento. Giro decolonial.

RESUMEN: En este artículo se explora el tema de la interculturalidad en la educación desde las contribuciones de la producción del Grupo Modernidad/Colonialidad, en la perspectiva de la descolonialidad. Resulta de un proceso de discusión llevada a cabo por el colectivo de investigadores asociados al Grupo de Investigación en Educación Intercultural del Unilasalle. Lanzase mano de la literatura disponibles para la construcción de la reflexión, con especial énfasis en los textos Mignolo, Quijano y Restrepo / Rojas. Los supuestos de estos pensadores apuntan a la proposición de "otra episteme, " pensado desde el lugar de lo subalternizado. Se hace notar que la educación intercultural constituye posible factor de la descolonización, en referencia a la construcción de "otra sociedad" mediante la superación de viejos discursos, estructuras

${ }^{1}$ Centro Universitário La Salle (Unilasalle), Canoas - RS - Brasil. Doutorando em Educação. E-mail: steffen@pvsinos.com.br.

${ }^{2}$ Centro Universitário La Salle (Unilasalle), Canoas - RS - Brasil. Professor do PPGEDU Unilasalle. Pesquisador bolsista PQ CNPq. Doutor em Educação. E-mail: gilberto.ferreira65@gmail.com.

RIAEE - Revista Ibero-Americana de Estudos em Educação, Araraquara, v. 13, n. 1, p. 140-154, jan./mar., 2018. 
de exclusión y actitudes discriminatorias. En esta perspectiva, la interculturalidad fomenta la coexistencia de los sujetos y las sociedades plurales y de múltiples culturas. Sin embargo, la realidad en el campo de la educación intercultural sigue siendo un reto en la búsqueda de "otro mundo posible".

PALABRAS CLAVE: Descolonialidad. Interculturalidad. Educación intercultural. Geopolítica del Conocimiento. Giro Decolonial.

ABSTRACT: This article explores the question of interculturality in the field of education since the contributions from the production of the Modernity / Coloniality Group from the perspective of decoloniality. It results from a process of discussion held by the collective of researchers linked to the Research Group on Intercultural Education of Unilasalle. The literature is available for the construction of the reflection, with special emphasis on the texts of Mignolo, Quijano and Restrepo / Rojas. The assumptions of these thinkers point to the proposition of an "other episteme," thought from the place of the subalternized. It can be seen that intercultural education constitutes a possible propelling factor for decolonization, referring to the construction of a "different society" by overcoming old discourses, exclusionary structures and discriminatory attitudes. From this perspective, interculturality fosters the coexistence of plural subjects and societies, of multiple cultures. Nevertheless, reality in the field of intercultural education remains a challenge in the search for a "possible other world".

KEYWORDS: Decoloniality. Interculturality. Intercultural education. Geopolitics of knowledge. Decolonial spin.

\section{Introdução}

Este artigo trata da interculturalidade na perspectiva da descolonialidade, tema que se insere na tendência contemporânea de investigações e reflexões sobre um pensamento "outro" realizado de um lugar "outro", com pretensão distinta da modernidade eurocêntrica. Ao pensar a geopolítica do conhecimento, os pesquisadores do Grupo Modernidade/Colonialidade (GM/C) buscam consolidar uma episteme fundada na pluriversalidade. Tem-se como objetivo trazer algumas ideias e pressupostos do GM/C, pensados desde reflexões e debates realizados no Grupo de Pesquisa em Educação Intercultural, do PPGEdu UNILASALLE.

Metodologicamente, este texto resulta de um estudo de cunho bibliográfico exploratório, com reflexões a partir de aportes teóricos de pensadores do GM/C e afins. Nesta pesquisa contempla-se o debate instaurado no contexto latino-americano, considerando a rica e complexa reflexão acumulada nos diferentes países da região. Uma imersão na literatura permitiu vislumbrar a complexidade teórica da produção existente e da diversidade de experiências formativas desencadeadas nas diferentes 
nações latino-americanas. Mais além, esse percurso proporcionou o contato com uma produção inspiradora, dinamizando epistemologicamente o trabalho proposto.

Mesmo com uma leitura seletiva realizada até o momento, percebe-se que pensar a interculturalidade na perspectiva da descolonialidade é tarefa complexa e desafiadora, porém possível e necessária no contexto atual. Como afirmam Mignolo e Tlostanova (2009, p. 19): "El pensamiento desde el borde y el giro des-colonial son una ruta hacia un futuro posible."

Este texto traz, de forma objetiva, alguns conceitos fundantes da descolonialidade em articulação com a interculturalidade. A partir de textos selecionados, no tópico $O$ movimento da descolonialidade abordam-se conceitos como modernidade, colonialidade, colonização, colonialismo, descolonização, descolonialidade e "giro decolonial" ou "inflexão decolonial". Em A interculturalidade em perspectiva é pensada a interculturalidade na perspectiva da descolonialidade. No tópico Desafios ao "paradigma outro" são apresentados alguns questionamentos em relação à proposta do GM/C. As considerações finais trazem possibilidades, desafios e contribuições para o avanço do conhecimento científico sobre a temática em questão.

\section{O movimento da descolonialidade}

Pressupostos teóricos do GM/C constituem-se em referencial para a tentativa de compreender a experiência latino-americana na perspectiva da educação intercultural, inclusive com seus impactos nas políticas de formação de educadores e nas práticas educacionais.

O GM/C é integrado por Aníbal Quijano (Peru), Walter Mignolo (Argentina), Enrique Dussel (Argentina), Catherine Walsh (norte-americana radicada no Equador), Nelson Maldonado-Torres (Porto Rico), Daniel Mato (Venezuela), Fernando Coronil (Venezuela), Edgardo Lander (Venezuela), Arturo Escobar (Colômbia), Santiago Castro-Gómez (Colômbia) e outros. Trata-se de uma "coletividade de argumentação" que atua coletivamente em relação a conceitos e estratégias, porém, com ênfases e trajetórias distintas. Não obstante, o grupo tem configurado um projeto intelectual e político chamado de "projeto decolonial" (RESTREPO; ROJAS, 2010).

Walter Mignolo, um dos intelectuais expoentes do grupo prefere referir-se a este coletivo como a um Programa de Investigação, ou seja, um coletivo que se mobiliza para estudar, analisar um ponto em comum, qual seja: o processo de colonização com

RIAEE - Revista Ibero-Americana de Estudos em Educação, Araraquara, v. 13, n. 1, p. 140-154, jan./mar., 2018. 
vistas à descolonização do conhecimento, realizando/propondo o "giro decolonial". Esta dinâmica constitui-se como um dos grandes pressupostos que vem mobilizando a reflexão e garantindo a vitalidade na discussão. Nas palavras do próprio Mignolo:

[...] la descolonialidad se convirtió en la expresión común emparentada con el concepto de colonialidad y se extendió la colonialidad del poder (económico y político) a la colonialidad del conocimiento y a la colonialidad del ser (de género, sexualidad, subjetividad y conocimiento); éstos fueron incorporados al vocabulario básico de los miembros del proyecto de investigación. Últimamente, y a instancias de Edgardo Lander, se agregó la esfera de la colonialidad de la naturaleza (2010, p. 11).

O referido projeto tem repercutido em toda a América Latina, encontrando simpatizantes também no Brasil, como é o caso de Luciana Ballestrin, cujas produções integram o conjunto de textos analisados. Ressalta-se, entretanto, que o Brasil não tem representantes no $\mathrm{GM} / \mathrm{C}$, o que suscita rápidas considerações.

Historicamente, o Brasil apresenta sérias dificuldades de inserção na América Latina. Um dos principais fatores que se vislumbra é o lugar para/de onde se olha. Enquanto o Brasil se volta para o Atlântico Norte, de costas para a América Hispânica, os países hispano-americanos olham desde a América Latina. Apesar de consideráveis semelhanças no processo de formação das nações latino-americanas, tais como os mais de três séculos de colonização ibérica, os efeitos da colonialidade, as influências de outras metrópoles europeias e a intervenção dos Estados Unidos, persiste um estranhamento da sociedade brasileira em relação às demais. Tal situação é evidenciada pela negação do sentimento de pertencimento e da inserção identitária. Fundamentalmente, o tipo de colonização implementado por Portugal e os processos de independência contribuíram para que o Brasil ficasse de costas para os seus vizinhos. Pensa-se que a aproximação entre as nações seja possível, mediante um reposicionamento da intelectualidade brasileira, a busca de uma efetiva integração na área educacional e a consolidação de uma "episteme outra".

Os pensadores da modernidade/colonialidade adotaram a expressão "giro decolonial" ou "inflexão decolonial" para definir o projeto, trazendo a noção de virada para expressar a transformação epistêmica em relação à colonialidade. Assim, "giro decolonial”, termo cunhado por Maldonado-Torres, “[...] basicamente significa o movimento de resistência teórico e prático, político e epistemológico, à lógica da modernidade/colonialidade" (BALLESTRIN, 2013, p. 105). Em outras palavras, o "giro 
decolonial" constitui-se num redimensionamento epistêmico, questionando a racionalidade antropocêntrica. Trata-se, na visão da autora, de um giro epistêmico geopolítico, isto é, um projeto político que busca respostas às lógicas da colonialidade do poder, do ser e do saber por meio de outras experiências, denunciando a permanência das relações de colonialidade encontradas no ocidentalismo, no eurocentrismo e no liberalismo dominantes.

Para Mignolo (2007), “[...] el pensamiento decolonial emergió en la fundación misma de la modernidad/colonialidad como su contrapartida.” (p. 27). Segundo ele, a América Latina é uma invenção que se insere no processo de constituição da modernidade. É, portanto, fruto da colonização cultural.

O "giro decolonial", na expressão de Maldonado-Torres (2008), mostra a descolonização como um projeto inacabado, sendo apenas o início de uma mudança radical. Para o pensador,

El concepto de giro des-colonial en su expresión más básica busca poner en el centro del debate la cuestión de la colonización como componente constitutivo de la modernidad, y la descolonización como un sin número indefinido de estrategias y formas constestatarias que plantean un cambio radical en las formas hegemónicas actuales de poder, ser, y conocer (MALDONADO-TORRES, 2008, p. 66).

A descolonização do poder, do saber e do ser somente é viável, segundo o referido autor, mediante uma atitude descolonial, isto é, uma postura crítica ante a colonialidade e suas implicações.

Faz-se necessário, aqui, esclarecer os principais conceitos que integram esta reflexão. Colonialismo consiste no processo de dominação político-administrativa que visa garantir a exploração do trabalho e das riquezas das colônias em benefício das metrópoles. Já colonialidade é um fenômeno histórico complexo, relativo a um padrão de poder global, que naturaliza hierarquias (territoriais, raciais, culturais e epistêmicas), reproduzindo relações de dominação e subalternização. Para Restrepo e Rojas (2010), a colonialidade constitui-se no "lado obscuro" da modernidade, esta associada ao colonialismo. Nesta direção a obra de Albert Memmi (2007) faz uma escavação arqueológica na subjetividade, revelando de forma crua os efeitos da colonialidade na construção de identidades culturais. São pertencimentos que se apregoam como essenciais, ancorados na ilusão "real" da supremacia de uma cultura/ "raça" sobre outras. Ainda que retratando a realidade da Tunísia, esta obra facilmente revela conexões com outras realidades que sofreram o processo de opressão gerado pela

RIAEE - Revista Ibero-Americana de Estudos em Educação, Araraquara, v. 13, n. 1, p. 140-154, jan./mar., 2018. 
colonização e amargam os efeitos da colonialidade que insiste em se perpetuar no tempo presente, diz o autor: "eu era uma espécie de mestiço da colonização, que compreendia a todos porque não pertencia a ninguém" (p. 21). Deve-se distinguir, também, os termos descolonização e decolonialidade. Descolonização se refere ao processo de independência política de uma colônia (superação do colonialismo), enquanto decolonialidade diz respeito a um processo que busca a transcendência da modernidade/colonialidade.

Restrepo e Rojas (2010) abordam a "inflexão decolonial” na mesma perspectiva de um "paradigma outro", criticando a colonialidade em sua tripla dimensão: a colonialidade do ser (inferiorizando seres humanos diferentes), do saber (marginalizando sistemas de conhecimento diferentes) e do poder (hierarquizando grupos humanos e lugares para explorá-los). Conforme os autores, a "inflexão decolonial" - ou "giro decolonial" - contém alguns traços centrais defendidos pela "comunidade de argumentação", que são: a) a distinção entre colonialismo e colonialidade; b) a colonialidade como o lado obscuro da modernidade; c) a problematização dos discursos eurocentrados e intramodernos da modernidade; d) o pensar em termos de sistema mundializado de poder; e) a "inflexão decolonial" como um paradigma outro; e f) a "inflexão decolonial" visa consolidar um "projeto decolonial".

$\mathrm{Na}$ perspectiva dos autores supracitados, a "inflexão decolonial" não é uma inversão dentro da ordem dicotômica regida pela modernidade, assumindo o lugar do paradigma hegemônico. O que a "inflexão decolonial” busca é mudar as condições de conservação em termos epistêmicos e de poder (RESTRPO; ROJAS, 2010). Esse novo paradigma - teoria descolonial - critica o eurocentrismo e sua teoria dominante, propondo o diálogo em nível de igualdade entre colonizado e colonizador. A "inflexão decolonial" não visa à homogeneização em nome dos subalternos coloniais, não propõe outra generalização.

Para Grosfoguel (2006), “inflexão decolonial” não é uma mera crítica antieuropeia, até porque os colonizados também estão inseridos como ocidentais em diversas categorias, estando, portanto, contaminados pela colonialidade. $\mathrm{O}$ autor alerta para a necessidade de se superar a modernidade eurocêntrica sem descartar o melhor da modernidade. E é justamente aí que assume importância um "paradigma outro", não meramente um outro modelo epistêmico. Assim sendo, a "inflexão decolonial” é considerada, por seus pensadores, não como um novo paradigma, mas sim como um 
"paradigma outro", questionando a episteme eurocêntrica com seu pretenso caráter de universalidade e propondo a pluriversalidade do saber. Para Mignolo (2008), o caminho para o futuro ante a colonialidade é a desobediência epistêmica, isto é, a proposição de um pensamento descolonial. Segundo Quijano (1992), a crítica do paradigma europeu da racionalidade/modernidade é necessária e urgente, mediante a descolonização epistemológica, possibilitando a liberação das relações interculturais e o intercâmbio de experiências. Para ele, "A descolonização é o piso necessário de toda revolução social profunda" (QUIJANO, 2002, p. 17).

Escobar (2003) caracteriza o trabalho do GM/C como um projeto que busca configurar um espaço outro de produção do conhecimento, um "pensamento outro", isto é, "um paradigma outro" num outro mundo possível. O conceito "pensamento outro" foi criado pelo sociólogo marroquino Abdelkebir Khatibi, refletindo a partir da decolonialidade e propondo a construção de outro modo de poder, de ser e de saber, diferente do implantado pela colonialidade. "Pensamento outro" parece ser mais adequado para expressar o que o GM/C designa como "paradigma outro", até mesmo por se tratar de um conceito ainda não plenamente consolidado. Entretanto, para Mignolo (2003), “'Un paradigma otro', complementário a la transición paradigmática, emerge, en su diversidad, en y desde las perspectivas de las historias coloniales [...]" (p. 22). Esse "paradigma outro" não se coaduna com a ideia de unidade, como no pensamento da modernidade. Os projetos do "paradigma outro" têm em comum a crítica à modernidade/colonialidade, sem reproduzir o caráter de universalidade. "El giro epistémico decolonial es una consecuencia de la formación e instauración de la matriz colonial de poder [...]” (MIGNOLO, 2007, p. 28).

Conforme Quijano (2002, p. 4), o atual padrão de poder mundial consiste na articulação entre a colonialidade do poder, o capitalismo, o Estado e o eurocentrismo. Racismo, controle do trabalho, dominação política e eurocentralização do padrão de poder caracterizam, respectivamente, as categorias supracitadas. Para Mignolo (2007), "La actualidad pide, reclama, un pensamiento decolonial que articule genealogias desperdigadas por el planeta y ofrezca modalidades económicas, políticas, sociales y subjetivas 'otras"” (p. 45). E aqui se inscreve uma outra concepção de cultura e de sociedade - a interculturalidade.

\section{A interculturalidade em perspectiva}

RIAEE - Revista Ibero-Americana de Estudos em Educação, Araraquara, v. 13, n. 1, p. 140-154, jan./mar., 2018. 
No debate da interculturalidade é preciso, inicialmente, estabelecer distinções entre termos e/ou enfoques. Conforme Silva (2006), utiliza-se o termo “[...] multiculturalidade para designar a realidade de grupos culturais distintos convivendo em uma mesma sociedade.” (p. 145). Mas, convivência não é garantia de respeito aos diferentes ou de aceitação do "outro". Já "[...] a interculturalidade se revela potencialmente como um projeto de intervenção a ser construído de forma intencional.” (SILVA, 2006, p. 145). Há, portanto, proposta de intervenção na realidade multicultural, buscando um intercâmbio mutuamente enriquecedor. Para Salas Astrain (2010), “A interculturalidade não se confunde com o conceito de multiculturalismo. De modo geral, o multiculturalismo se relaciona à tentativa de caracterizar a diversidade de culturas coexistentes em uma sociedade, e de seus traços característicos” (p. 9). O multiculturalismo postula pelo reconhecimento das diferenças, porém pode consagrar determinada cultura como hegemônica. "A interculturalidade, além de reconhecer as diferenças, destaca aspectos que proporcionam o diálogo e a interação mútua entre as culturas" (SALAS ASTRAIN, 2010, p. 10). No mesmo sentido tem-se: “[...] a educação cultural preconiza a intervenção propositiva e desafiadora no trabalho com as diferenças culturais para além do reconhecimento" (SILVA, 2006, p. 146). Interculturalidade, portanto, é mais do que a coexistência de culturas; implica diálogo cultural, o que pressupõe miscigenação de diversas culturas.

Desde as preocupações no universo da educação e da interculturalidade é que a pesquisadora Catherine Walsh, da Universidade Andina Simón Bolívar, Sede Equador, vem se debruçando de forma intensa. Seus estudos potencializam a educação intercultural na perspectiva defendida pelo Grupo M/C.

Más que "incluir" de manera multiculturalista, el esfuerzo ha sido de construir, posicionar y procrear pedagogías que apuntan el pensar "desde" y "con", alentando procesos y prácticas "praxísticas" de teorización —del pensar-hacer- e interculturalización que radicalmente desafían las pretensiones teórico-conceptuales y metodológicas-académicas, incluyendo sus supuestos de objetividad, neutralidad, distanciamiento y rigor (2012, p. 66).

Assim apostamos na compreensão de interculturalidade defendida por Walsh (2012) quando afirma que:

[...] se entiende como una estrategia, acción y proceso permanentes de relación y negociación entre, en condiciones de respeto, legitimidad, simetría, equidad e igualdad. Pero aún más importante es su entendimiento, construcción y posicionamiento como proyecto

RIAEE - Revista Ibero-Americana de Estudos em Educação, Araraquara, v. 13, n. 1, p. 140-154, jan./mar., 2018 
político, social, ético y epistémico -de saberes y conocimientos -, que afirma la necesidad de cambiar no sólo las relaciones, sino también las estructuras, condiciones y dispositivos de poder que mantienen la desigualdad, inferiorización, racialización y discriminación (p. 66).

Enfatiza-se que a interculturalidade deve ser vista sob a perspectiva das relações "entre" as diferenças, entre os povos e culturas, entre os grupos distintos, rompendo com a perspectiva de uma noção vista sob a ótica de uma ou outra cultura. A interculturalidade se propõe a mais do que reconhecer e tolerar as diferenças, é preciso intervir, transformar estruturas sociais injustas, reconstruir sob outras bases, estabelecendo outras/novas formas de relações, de existir e co-existir. Aprender a ser, estar e (con) viver com o outro.

O tema interculturalidade, inscrito no "projeto decolonial", ganha importância com os estudos de Catherine Walsh. A pesquisadora entende interculturalidade como a possibilidade de diálogo entre as culturas, pensada na perspectiva crítica "[...] como proyecto político-social-epistémico-ético y como pedagogia decolonial [...]" (WALSH, 2010, p. 76). Trata-se do que a pesquisadora conceitua como interculturalidade crítica, entendida como projeto de transformação social a partir do campo educacional. Para ela, a descolonialidade é "[...] estrategia, acción y meta [...]" da interculturalidade. Isto é, a interculturalidade como processo e projeto pretende construir "modos outros" de poder, saber e ser. Interculturalidade significa, portanto, “[...] una forma 'otra' de pensar y actuar com relación a y en la modernidad/colonialidad." (WALSH, 2006, p. 35). Desde essa perspectiva, Walsh toma como ponto de partida o problema estrutural-colonialracial, reconhecendo que a diferença se constrói no interior de “[...] una estrutura e matriz colonial de poder racionalizado y jerarquizado [...]” (WALSH, 2010, p. 78). Assim, a interculturalidade deve ser entendida como projeto voltado à transformação estrutural e sócio-histórica para todos: “[...] la interculturalidad es práctica política y contrarrespuesta a la geopolítica hegemónica del conocimiento; es herramienta, estrategia y manifestación de una manera 'otra' de pensar y actuar" (WALSH, 2005a, p. 47).

Tal concepção é corroborada por Candau e Russo (2010, p. 166): “A interculturalidade é então concebida como uma estratégia ética, política e epistêmica. Nessa perspectiva, os processos educativos são fundamentais". Por meio dos processos educativos, questiona-se a colonialidade e propõe-se uma sociedade "outra". Para Becka (2010), "Interculturalidade contém um potencial crítico que questiona, critica e estrutura os diversos contextos" (p. 57-58). Segundo a autora, a contextualidade condiciona e 
desafia a interculturalidade, pois os falantes integrantes do diálogo intercultural são portadores de contextos espaço-temporais.

Para Fornet-Betancourt (2004), filósofo cubano, a interculturalidade faz parte da história latino-americana, mas permanece uma questão pendente. Interculturalidade designa a postura segundo a qual as pessoas se capacitam para viver com os "outros". "Daí que se trata de uma atitude que abre o ser humano e o impulsiona a um processo de reaprendizagem e recolocação cultural e contextual" (FORNET-BETANCOURT, 2004, p. 13). Para o filósofo, o diálogo ocupa centralidade. Todavia, no caso da América Latina, esse elemento relacional ainda é limitado e insuficiente. O diálogo intercultural precisa ser transversal, isto é, da periferia à periferia. Os iguais precisam dialogar.

Educação intercultural pressupõe superar o individualismo, os velhos discursos, as estruturas excludentes e as posturas discriminatórias em prol de um trabalho cooperativo, colaborativo, reflexivo e dialógico. Sob essa ótica, interculturalidade crítica possibilita a convivência de realidades plurais, o questionamento de discursos hegemônicos, padronizações e binarismos, bem como a desconstrução, problematização e relativização de estruturas e práticas sociais.

Cabe destacar o papel da escola e do currículo no que se refere à implementação de um processo educacional verdadeiramente intercultural. A escola é a instituição social em cujo espaço se processa tanto a produção quanto a reprodução da cultura, podendo ocorrer tanto a desconstrução de práticas discriminatórias em relação aos diferentes quanto a naturalização das desigualdades. Daí que o currículo escolar precisa ser construído de forma a possibilitar "olhares outros" e "abordagens outras", tendo em vista a representação da realidade e os tipos de subjetividades e identidades que pretende produzir. Um currículo intercultural requer conteúdos, procedimentos, atitudes e relações que privilegiem o protagonismo do estudante no contexto e/ou espaço escolar. Pensar a educação nessa perspectiva não é idealismo; é possível.

\section{Desafios ao "paradigma outro"}

Questionar a modernidade desde a perspectiva da colonialidade parece ser, conforme Restrepo e Rojas (2010), o problema central para a "inflexão decolonial": “[...] no existe modernidad sin colonialidad [...]" (p. 205). Para os autores, a "inflexão decolonial" critica o eurocentrismo, mostrando o lado visível de suas retóricas. Entretanto, há o lado obscuro construído por práticas de violência da colonialidade. Eis

RIAEE - Revista Ibero-Americana de Estudos em Educação, Araraquara, v. 13, n. 1, p. 140-154, jan./mar., 2018 
um paradoxo da "inflexão decolonial": seus proponentes discutem a questão, mas continuam reproduzindo as narrativas da modernidade. "Nos parece necesario revisar ciertos argumentos que operan como certezas y punto de anclaje de muchos otros planteamientos de la inflexión decolonial” (RESTREPO; ROJAS, 2010, p. 208).

Também Yehia questiona o discurso da descolonialidade:

[...] ¿al enmarcar nuestros argumentos en el pensamiento decolonial y usar categorías como "decolonial", "no moderno" o "transmoderno" no estamos también contribuyendo a reproducir las pretensiones universalistas de la modernidad? (YEHIA, 2007, p. 109).

Portanto, como sugere Yehia, o "paradigma outro" parece continuar operando segundo o discurso hegemônico por ele criticado. É mister, pois, transcender a tendência a reproduzir a racionalidade contestada. Para a autora, os interlocutores da “inflexão decolonial” estão constituídos predominantemente por intelectuais ocidentais, os quais não representam os subalternizados.

Na perspectiva da geopolítica do conhecimento, Boaventura de Sousa Santos propõe considerar-se "[...] quién produce el conocimiento, en qué contex to lo produce y para quén lo produce" (2009, p. 340). Tal proposição vem corroborar as preocupações de Yehia: quem são os defensores da "inflexão decolonial", de que comunidade fazem parte, de onde falam, a quem falam e de que tratam? Seria um "Penso de onde estou!". Rita Laura Segato (2014), professora da Universidade de Brasília, em interessante artigo, onde analisa os principais conceitos de Aníbal Quijano, é no mínimo provocativa. Recorrendo às suas palavras:

La creativa figura de Aníbal Quijano nunca há aceptado migrar al norte - Donde van a morir los elefantes, [...] y há permanecido empecinadamente em el Perú, excepto em breves períodos de exilio o por algunas semanas al año para desenpeñarse como docente al Centro Fernand Braudel de la State University of New York em Birghantom, fundado por su gran amigo Immanuel Wallerstein". (p. 37-8)

A partir de produções textuais de Maldonado-Torres, Restrepo e Rojas sintetizam o que chamam de paradoxo da "inflexão decolonial":

La paradoja es que se habla todo el tiempo a nombre de los subalternizados coloniales, de las prácticas de racismo y exclusión, de los negros e indígenas, se cuestiona todo el tiempo el eurocentrismo y los silencios e invizibilizaciones históricas, epistémicas y ontológicas que introduce... pero, y i quién está hablando? ¿ cómo lo está haciendo? ¿de qué está hablando? ¿para quién habla? ¿para qué, en últimas, habla como lo está haciendo? (RESTREPO; ROJAS, 2010, p. 201-202).

RIAEE - Revista Ibero-Americana de Estudos em Educação, Araraquara, v. 13, n. 1, p. 140-154, jan./mar., 2018. 
Esses questionamentos encerraram em si as preocupações e os cuidados que devem ter os proponentes de uma "episteme outra", um "paradigma outro", evitando a reprodução de narrativas que são combatidas em relação à racionalidade hegemônica. Em suma, é preciso intensificar os diálogos entre os colonizados, numa perspectiva intercultural crítica, permitindo que se crie outros modos de viver, construindo outras formas de compreensão a partir de aparatos práticos e intelectuais que não se amparam na perspectiva do pensamento que orientou a colonização. A desobediência epistêmica proposta é justamente o primeiro passo para instituir espaços de interculturalidade nas trocas e nos diálogos que fecundam novos modos de pensar, e que talvez por isso mesmo, marquem a diferença em relação ao pensamento que historicamente se manteve hegemônico e absoluto. Neste sentido também se poderia propor o diálogo com o pensamento que forjou a modernidade, mas diga-se, sem prioridade.

\section{Considerações finais}

A “inflexão decolonial" (ou "giro decolonial") consiste numa virada fundamentalmente epistêmica, questionando a modernidade eurocêntrica e propondo uma "episteme outra" baseada na pluriversalidade. Trata-se de um projeto político que vai para além da compreensão das lógicas da colonialidade desde um lugar "outro". Propõe a descolonialidade do poder, do saber e do ser, como estratégia e recurso para a construção de um pensamento outro.

Os integrantes do GM/C acreditam que a descolonialidade seja o caminho para a interculturalidade. Entendem que a interculturalidade crítica constitui-se como estratégia de ordem política, social, ética e epistêmica para a transformação da realidade latino-americana e de todas as sociedades subalternizadas pela modernidade/colonialidade, e em específico com particular interesse ao campo da educação. Esse trabalho coletivo tem possibilitado leituras analíticas e reflexivas, bem como tem apresentado medidas propositivas e pragmáticas. Dentre as proposições, destacam-se a produção de uma reflexão crítica sobre os efeitos da modernidade/colonialidade nas áreas subalternizadas, a questão racial na América Latina e a questão da diferença colonial, a constatação da continuidade da colonização e do imperialismo mediante a colonialidade do poder, do saber e do ser, e, como maior contribuição, o projeto epistêmico na perspectiva "decolonial".

RIAEE - Revista Ibero-Americana de Estudos em Educação, Araraquara, v. 13, n. 1, p. 140-154, jan./mar., 2018 
Os discursos dos proponentes do "paradigma outro" convergem para uma opção descolonial caracterizada pela desobediência político-epistêmica, pela solidariedade entre os subalternizados coloniais, pela busca da pluriversalidade e pela construção de espaços de diálogo em igualdade de condições. Essa ideia requer, acima de tudo, mudança radical do sujeito embasada numa atitude des-colonial de estranhamento e espanto ante a naturalização das desigualdades historicamente infringida pela colonização e temporalmente presentificadas.

Em que pese a relevância das ações e estratégias do "projeto decolonial", persistem muitos questionamentos sobre a viabilidade de concretude da virada e muitos desafios a serem superados. É possível a integração dos povos subalternizados em prol de objetivos comuns? É viável um projeto pluriversal integrador? De que maneira a educação intercultural pode, efetivamente, contribuir para a descolonialidade? Ou ainda, invertendo a pergunta: de que maneira a descolonialidade pode, via a interculturalidade, ser uma estratégia efetiva e eficiente na construção de uma proposta educativa descolonizadora e decolonial? Uma "episteme outra" poderá consolidar-se e conquistar espaço no mundo atual? Buscar respostas a esses questionamentos é tarefa que o GM/C assume e que o Grupo de Pesquisa em Educação Intercultural do PPGEdu/Unilasalle soma-se, ampliando a perspectiva da crença de que um "mundo outro é possível”.

\section{REFERÊNCIAS}

BALESTRIN, Luciana. América Latina e giro decolonial. Revista Brasileira de Ciência Política, Brasília, n. 11, p. 89-117, maio/ago., 2013.

BECKA, Michelle. Interculturalidade no pensamento de Raúl Fornet-Betancourt. São Leopoldo: Nova Harmonia, 2010.

CANDAU, Vera Maria Ferrão.; RUSSO, Kelly. Interculturalidade e educação na América Latina: uma construção plural, original e complexa. Rev. Diálogo

Educacional, Curitiba, v. 10, n. 29, p. 151-169, jan./abr., 2010.

ESCOBAR, Arturo. Mundos y conocimientos de otro modo: el programa de investigación de modernidad/colonialidad latinoamericano. Tabula Rasa, Bogotá Colômbia, n. 1, p. 51-86, jan./dez., 2003.

FORNET-BETANCOURT, Raúl. Interculturalidade: críticas, diálogo e perspectivas. São Leopoldo: Nova Harmonia, 2004.

GROSFOGUEL, Ramón. La descolonización de la economía política y los estudios postcoloniales. Transmodernidad, pensamiento fronteirizo y colonialidad global.

Tabula Rasa, Bogotá - Colômbia, n. 4, p. 17-48, jan./jun., 2006.

RIAEE - Revista Ibero-Americana de Estudos em Educação, Araraquara, v. 13, n. 1, p. 140-154, jan./mar., 2018 
MALDONADO-TORRES, Nelson. La descolonización y el giro des-colonial. Tabula Rasa, Bogotá - Colômbia, n. 9, p. 61-72, jun./dez., 2008.

MEMMI, Albert. Retrato do Colonizado precedido pelo retrato do colonizador (Trad. Marcelo Jacques de Moraes). Editora Civilização Brasileira: Rio de Janeiro, 2007.

MIGNOLO, Walter D. Historias locales/diseños globales: colonialidad, conocimientos subalternos y pensamiento fronterizo. Madrid: Ediciones Akal, 2003.

MIGNOLO, Walter D. El pensamiento decolonial: desprendimiento y apertura - un manifesto. In: CASTRO-GÓMEZ, Santiago; GROSFOGUEL, Ramón. El giro decolonial. Reflexiones para una diversidad epistémica más allá del capitalismo global. Bogotá: Siglo del Hombre Editores, 2007. p. 25-45.

MIGNOLO, Walter D. Desobediência epistêmica: a opção descolonial e o significado de identidade em política. Cadernos de Letras da UFF, Niterói - RJ, n. 34, p. 287 324, 2008.

MIGNOLO, Walter D.; TLOSTANOVA, Madina. Habitar los dos lados de la frontera/teorizar en el cuerpo de esa experiencia. Revista Ixchel, México, 2009.

MIGNOLO, Walter. Desobediencia epistémica: retórica de la modernidad, lógica de la colonialidad y gramática de la descolonialidad. Buenos Aires: Ediciones del Signo, 2010 .

MUNSBERG, João Alberto Steffen. O ensino médio politécnico frente às demandas e perspectivas discentes. 2015. 193 f. Dissertação (Mestrado em Educação) - Centro Universitário La Salle, Canoas, 2015.

QUIJANO, Aníbal. Colonialidad y modernidad/racionalidad. Perú Indígena, Lima(?), n. 13(29), p. 11-20,1992.

QUIJANO, Aníbal. Colonialidade, poder, globalização e democracia. Novos Rumos, Marília, a. 17, n. 37, p. 4-28, 2002.

RESTREPO, Eduardo; ROJAS, Axel. Inflexión decolonial: fuentes, conceptos y cuestionamientos. Cauca - Colômbia: Editorial Universidad de Cauca, 2010.

SALAS ASTRAIN, Ricardo. Ética intercultural: (re)leituras do pensamento latinoamericano. São Leopoldo: Nova Harmonia, 2010.

SANTOS, Boaventura de Sousa. Uma epistemologia del Sur. México: Clacso-Siglo XXI, 2009.

SEGATO, Rita Laura. Aníbal Quijano y la perspectiva de la colonialidad del poder. In: QUIJANO, Aníbal (Org.) Des/colonialidad y bien vivir: un nuevo debate em américa Latina. Editorial Universitaria: Lima, 2014. p. 35-71. 
SILVA, Gilberto Ferreira da. Cultura(s), currículo, diversidade: por uma proposição intercultural. Contrapontos, Itajaí - SC, v. 6, n. 1, p. 137-148, jan./abr., 2006.

WALSH, Catherine. Interculturalidad, conocimientos y decolonialidad. Signo y Pensamien-to, Bogotá, v. XXIV, n. 46, p. 39-50, jan./jun., 2005a.

WALSH, Catherine. Introducción. In: WALSH, Catherine. Pensamiento crítico y matriz (de)colonial: reflexiones latinoamericanas. Quito: UASB - Abya Yala, 2005b.

WALSH, Catherine. Interculturalidad y (de)colonialidad: diferencia y nación de otro modo. In: Desarollo e interculturalidad, imaginario y diferencia: la nación en el mundo andino. Quito: Academia de la Latinidad, 2006, p. 27-43.

WALSH, Catherine. Interculturalidad crítica y educacion intercultural. In: VIANA, Jorge.; TAPIA, Luis.; WALSH, Catherine. Construyendo interculturalid crítica. La Paz: III - CAB, 2010. p. 75-96.

WALSH, Catherine. Interculturalidad y (de)colonialidad: Perspectivas críticas y políticas. Visão Global, Joaçaba, v. 15, n. 1-2, p. 61-74, jan./dez., 2012.

YEHIA, Elena. Descolonización del conocimiento y la práctica: un encuentro dialógico entre el programa de investigación sobre modernidad/colonialidad/decolonialidad latinoamericanas y la teoria actor-red. Tabula Rasa, Bogotá - Colômbia, n. 6, p. 85115, jan./jun., 2007.

\section{Como referenciar este artigo}

MUNSBERG, João Alberto Steffen.; FERREIRA DA SILVA, Gilberto. Interculturalidade na perspectiva da descolonialidade: possibilidades via educação. Revista Ibero-Americana de Estudos em Educação, Araraquara, v. 13, n. 1, p. 140154, jan./mar., 2018. E-ISSN: 1982-5587.

Submetido em: 22/12/2016

Revisões requeridas: 03/03/2017

Aceito em: 02/07/2017 